\title{
Accessible Design in Rural Health Care: Usability Profile of Outpatient Health Care Facilities in Rural West Virginia
}

\author{
Jordan Elliott Miller, MS' ${ }^{1}$, Chris Haddox, PhD'
}

ABSTRACT

The purpose of this research is to better understand the physical and environmental features of outpatient healthcare facilities that act as barriers to healthcare access in rural West Virginia and factors that contribute to non-compliance with the Americans with Disabilities Act (ADA). The research aims to explore the prevalence of barriers in rural West Virginian health facilities and the relationship between building characteristics (like the year of construction and original purpose) and accessibility. The researcher evaluated ten rural outpatient member-sites of the West Virginia Practice-Based Research Network using the Outpatient Health Care Usability Profile to measure essential features for a facility to be considered 'usable'. The results indicate that surveyed clinics scored an average of $73 \%$ in overall accessibility. Counters, restrooms, and exam rooms were the lowest scoring categories. The study found a moderate positive correlation between year of construction and mobility (Pearson $r$ $=0.765)$ and overall score $(r=0.637)$. This research supports the notion that physical and environmental barriers to healthcare access still exist and that older clinical buildings run a higher risk of being non-compliant with essential ADA items and thus contribute to barrier creation. This research design was approved by the West Virginia University Institutional Review Board (IRB), protocol number 1802995833.

\section{KEYWORDS}

Disability, Health Care, Rural, West Virginia, Accessibility, Design, Accessible Design
Author affiliations are listed at the end of this article.

Correspondence to: Jordan Elliot Miller, MS West Virginia University jem0031@mix.wvu.edu

\section{INTRODUCTION}

Equal access to public accommodations, including health care facilities, is a right afforded to everyone by the Americans with Disabilities Act (ADA) (1990). ${ }^{1}$ Many outpatient health care facilities are often non-compliant with relevant items from the ADA Accessibility Guidelines (ADAAG). ${ }^{2}$ As a result, patients with disabilities are less likely to participate in preventative care services and list physical access barriers as one of the many reasons. ${ }^{3}$ Rural facilities face an added barrier of distance, which is the most commonly identified barrier for rural patients receiving health care. ${ }^{4}$ The inherent remoteness of these facilities emphasizes the importance of quality care, as rural patients have less spatial access to health care alternatives.
In West Virginia, 43 of the state's 55 counties are considered rural with $38 \%$ of the population living in rural places. ${ }^{5}$ In addition, West Virginia has the highest rate of non-institutionalized working-age people with disabilities in the country and the secondhighest population of adults age 65 years or older, ${ }^{6}$ a population expected to increase $22 \%$ by the year $2030 .^{7}$

The purpose of this research is to better understand the usability profile of rural West Virginian outpatient health care facilities and factors that contribute to low levels of clinic physical accessibility. Facilities were evaluated using the Outpatient Health Care Usability Profile (OHCUP), a valid and reliable tool used to assess pertinent ADA items for people with disabilities. ${ }^{8}$ Researchers hypothesize a compliance rate not significantly different from $70 \%$ and 
anticipate patient lift/transfer devices, restrooms, exam rooms and parking lots will be consistent areas of non-compliance and that year of construction will positively correlate with usability scores. ${ }^{9}$ The research additionally seeks to explore the role building retrofitting plays on health care facility usability scores. The results of this research serve to validate and identify factors related to poor ADA compliance and to build a framework in identifying important and commonly non-compliant ADA items in outpatient health care.

\section{METHODS}

The research employed a descriptive and correlational design. Health care clinics were selected as part of a purposeful sample of facilities that were rural, diverse in terms of the health care system, and offered outpatient primary care services. Clinical partnerships were made through the West Virginia Practice-Based Research Network (WVPBRN). The Network's membership is made up of primary care providers from clinical sites from across West Virginia. These sites are mainly Federally Qualified Health Centers (FQHCs) or Rural Health Clinics (RHCs) that are often in remote locations and serve rural populations with limited access to medical resources. Rural was defined by Rural Urban Commuting Area (RUCA) codes 7.0 - 10.0, which are considered small rural areas. ${ }^{10}$ Twenty locations out of the 107 member-sites of the WVPBRN qualified for the study. Ten agreed to participate between September and November of 2018. All sites were independently owned or members of various and diverse health care systems. Clinics were contacted to submit preliminary information about the characteristics of their building including the year of construction, type of practice and whether the facility had been retrofitted to house medical offices.

Each facility was visited by a researcher who conducted the Outpatient Health Care Usability Profile (OHCUP), a valid and reliable (Kappa $=0.89$ ) 159-item tool that measures the usability of outpatient health care facilities. The OHCUP tool produces categorical results for mobility, sensory and cognitive disorders by evaluating relevant ADA Accessibility Guideline (ADAAG) items. The entirety of these items is considered the minimum threshold for a facility to be considered usable for people with disabilities. The tool evaluates 121 mobility items, 41 sensory items, and 8 cognitive items. Each item in the tool is evaluated and marked with a 0 or a 1. A 0 indicates that the facility demonstrated noncompliance with the ADA item and a 1 indicates that the facility was either fully compliant or that item was not applicable (N/A) in the facility (such as stairs or elevators in a single-story health clinic). 8 The total score out of 159 items represents the facility's overall score or usability profile. OHCUP is divided into sections (parking, doors, stairs, etc.) that are described as sub-categorical results in this research. A fifth category was created to account for variations that resulted from points awarded to unavailable items. The fifth "N/A adjusted" category removes all inapplicable items from each facility, producing a new total in which the overall score can be recalculated.

The mean of all facility scores in each of the five major categories was used to assess the usability profile of the sampled health care clinics. Results from each section of the OHCUP were calculated to better understand more specific areas of noncompliance. Specific items were also aggregated and discussed in terms of commonly non-compliant items. The correlational analysis measured the relationship between all five final OHCUP scores and year of construction as well as how the OHCUP scores were affected by the original purpose of the building.

Shapiro-Wilks W tests were used to assess the distribution of all the factors. Relationships of normally distributed variables were analyzed using parametric correlations (Pearson $r$ ) and variables that included data not normally distributed were analyzed using nonparametric correlation (Spearman's rho). In measuring the effect building purpose has on OHCUP scores, a t-test was used for parametric data and a nonparametric WilcoxonMann-Whitney Ranked Sums Test was conducted for data with variables that were not normally distributed.

Data were analyzed using JMP and SAS software (JMP ${ }^{\circledast}$, Version Pro 12.2, SAS Institute Inc., Cary, NC, 
Copyright $\odot 2015 ;$ SAS ${ }^{\circledR}$, Version 9.3, SAS Institute Inc., Cary, NC, Copyright @2002-2010). The significance criterion alpha for all tests was 0.05 . In all statistical analyses, the significance criterion alpha for all tests was 0.05 and a statistical trend was declared when $\mathrm{p}<0.1$.

\section{RESULTS}

The ten rural facilities were normally distributed in terms of year of construction $(p=0.053)$. Construction years ranged from 1919 to 2011, the sample mean construction year was 1982 and the sample median was 1994. All facilities offered outpatient health care services.

\section{Major Categorical Results}

Overall facilities averaged $83.08 \%$ (SD = 6.23) usable for people with mobility, sensory, or cognitive disabilities with a range from $70.44 \%$ to $93.71 \%$. After items scored N/A were removed, the facilities were evaluated on an average of 101 items. These N./A adjusted scores were considerably lower. The average of the N/A adjusted score was $73.40 \%$ (SD $=9.90$ ) with a range minimum of $52.00 \%$ and a maximum of $89.00 \%$. By adjusting for N/A the total number of items removed from calculation was 576 or 36.23 percent of the total item evaluated in every facility. When inapplicable items were removed the mean score for mobility was $73.49 \%$, sensory was $69.86 \%$, and cognitive was $81.97 \%$.
Table 1.

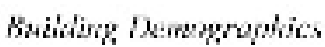
n $\%$

Independently owned

Yes

No

880

$2 \quad 20$

Type of praetice

Docurn's Oflive 5 so

$\begin{array}{lll}\text { Specialist Clinic } & 10\end{array}$

Hospi|al

General Outpatient $\quad 1 \quad 10$

Originally built to bouse medical offices

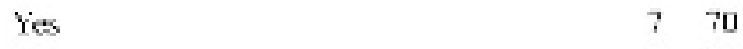

No 30

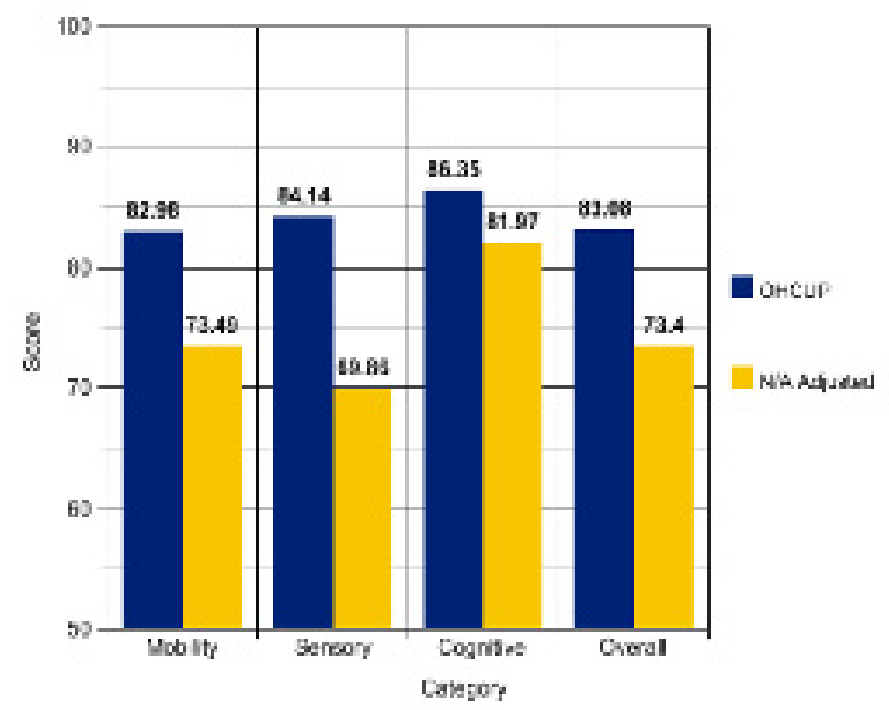

Sub-Categorical Results

Sub-categorical results consisted of 19 individual features of the facility. When these results are unadjusted, the categories that scored below the $83.08 \%$ overall score average include counters, lab specimen rooms, restrooms, exam rooms, signage, parking, and seating. Sub-categories that

\begin{tabular}{lllll}
\hline $\begin{array}{l}\text { Sub- } \\
\text { Category }\end{array}$ & $\begin{array}{l}\text { Total \# of } \\
\text { Applicable } \\
\text { Items }\end{array}$ & $\begin{array}{l}\text { Total } n_{1} \text { of } \\
\text { Items in } \\
\text { Compliance }\end{array}$ & $\%$ & Cl 95\% \\
\hline
\end{tabular}
fell below the mean N/A adjusted score of $73.40 \%$ are included in Table 2 . All subcategories featured in the first evaluation (not adjusted) are identified as highly non-compliant sub-categories in the N/A Adjusted evaluation

$\begin{array}{lllll}\text { Connters } & 13 & 4 & 30.76 & 10.36-61.12 \\ \text { Lab Specimen Rooms } & 199 & 132 & 65.34 & 59.25-75.37 \\ \text { Sigmage } & 98 & 65 & 66.33 & 55.99-88.73 \\ \text { Restrooms } & 181 & 122 & 67.40 & 59.99-74.06 \\ \text { Elevators } & 26 & 18 & 69.23 & 48.10-84.91 \\ \text { Parking } & 56 & 40 & 71.43 & 57.59-82.31 \\ \text { Exam Rooms } & 89 & 65 & 73.03 & 62.41-81.64\end{array}$

TABLE 2. Sub-Categorical Results (N/A Adjusted) $(M<73.40)$ 
except for seating which remained at $80.00 \%$ since all items evaluated were applicable at every location. Elevators are the only item added to the list; however, only two locations evaluated featured elevators.

Individual Items Commonly Found in Non-compliance

The following section evaluates individual items within the OHCUP to understand which items are most commonly found in non-compliance among surveyed facilities. Eighteen items are detailed in the table in order of how they appear in the OHCUP. Subcategories that contained items most commonly found in non-compliance include parking, signage, doors, counters, restrooms, emergency egress, exam rooms, and lab specimen rooms which include restrooms designated for sample collection.

\section{Effect of Building Age on Usability Scores}

The research also aimed to understand if the year of construction and original purpose correlate with facility usability profiles. Parametric correlations (Pearson $r$ ) were used to examine relationships of variables that were normally distributed (based on Shapiro-Wilk W test). Spearman's Rho was used to evaluate correlations for nonparametric data, which in this case only included cognitive scores. A Pearson correlation coefficient was computed to assess the relationship between year of construction and mobility, sensory, overall, and N/A adjusted scores of facilities.

Correlation between year of construction was statistically significant and moderately positively correlated with mobility scores $[r=0.765, n=10, p$ $=0.009$ ], N/A adjusted scores [ $r=0.6971, p=0.025]$, and overall scores [ $r=0.637, n=10, p=0.048]$. The sensory score was not correlated with year of construction. For nonparametric data in cognitive scores, there was no correlation between building year of construction.
Figure 2: Medizai Purpase effect on N/A Aajusted

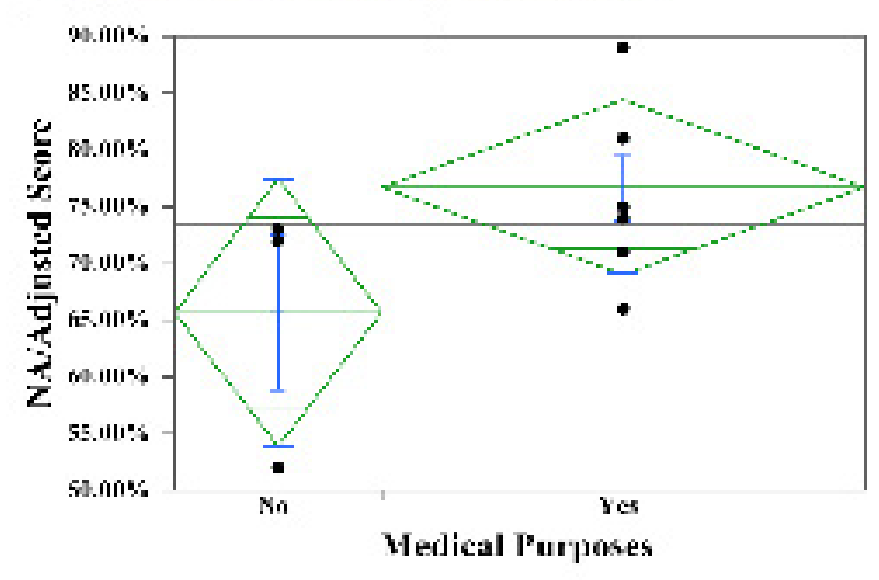

\section{rigure 5: Medicol Purpose effect on Overail score}

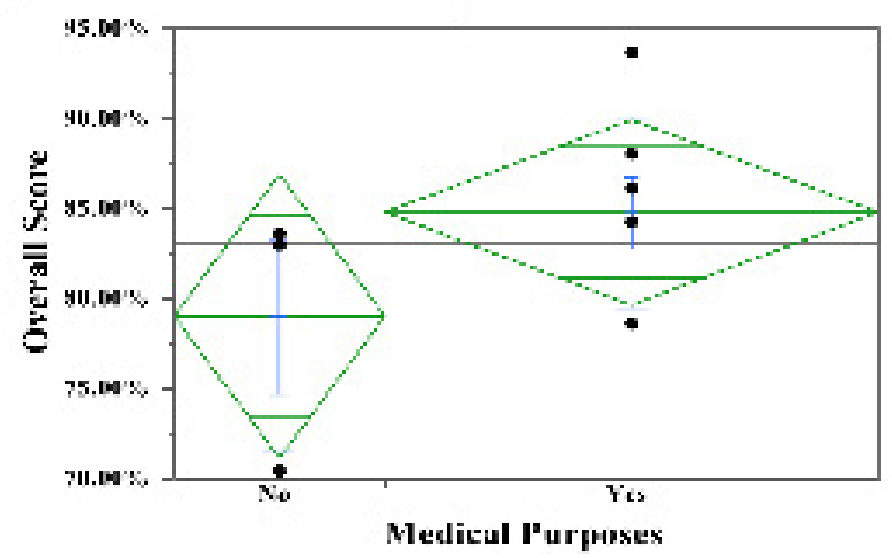

Figure 4: Medicol Purpase cifect an hability Secre

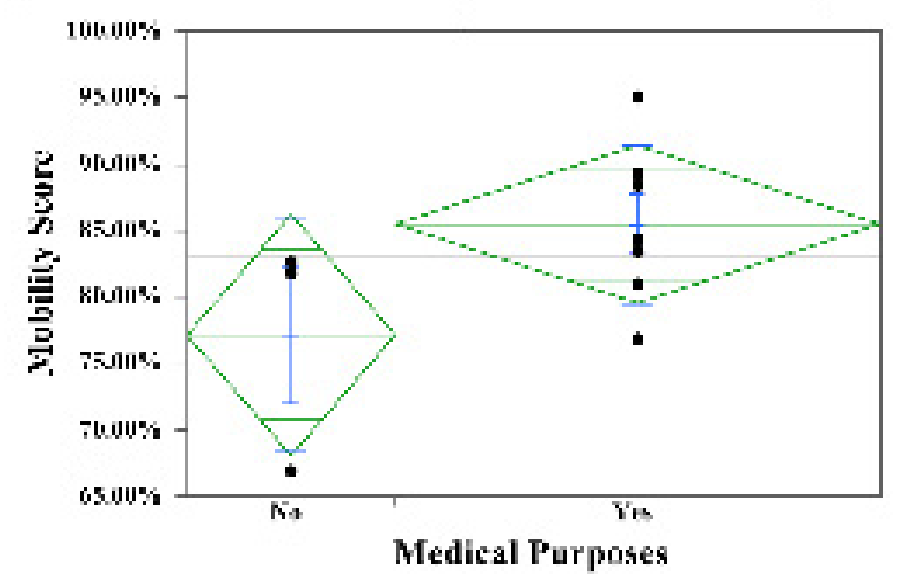

Figures 2-4: Mean Diamond and X-Axis Proportional graphs are produced by JMp statistical software. The graphs contain two diamonds and black dots, one diamond represents facilities designed for the purpose of housing medical offices (yes) and the other represents the facilities that were retrofitted to facilitate medical offices (no). Each black dot represents the OHCUP results for the ten facilities evaluated. The width of the diamond represents the proportional sample size, the midline represents the mean of the respective results, the top and bottom of the diamond represent $95 \%$ confidence intervals, and the green lines are overlap marks indicating where the two groups overlap at the given confidence. 
TABLE 3. Individual Items Commonly Found in Non-compliance ${ }^{8}$

\begin{tabular}{|c|c|c|c|c|}
\hline Suj Catceary & $16 \mathrm{~cm} *$ & OHCOP Itom Text & $\begin{array}{l}\forall \text { of Foeilities in } \\
\text { Non-compliance }\end{array}$ & $\begin{array}{l}\text { C1 } 95 \% \text { Lawer and Cpper } \\
\text { Far Item Non-compliance }\end{array}$ \\
\hline Parking & 2 & 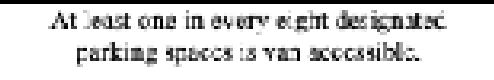 & 6 & $49.73 \quad 69.52$ \\
\hline \multirow[t]{2}{*}{ Bigmang. } & $a s$ & 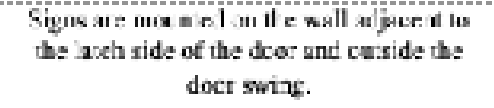 & 8 & $399.1-8.0 \%$ \\
\hline & $3 e$ & 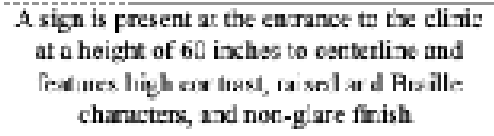 & 0 & $5543-59.95$ \\
\hline Doers & 41 & 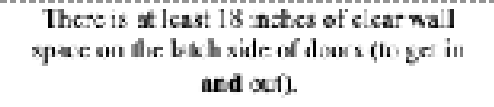 & 6 & $49.7 \mathrm{~J}-\mathrm{E} 9.52$ \\
\hline Comiders & 3 & 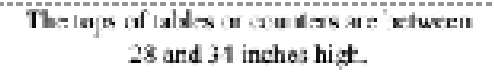 & 9 & 6. $97-5424$ \\
\hline \multirow[t]{4}{*}{ Restreatin } & 91 & $\begin{array}{l}\text { bite of the Joor, } 60 \text { ndtes ftom the floor to } \\
\text { the middle of the sign. }\end{array}$ & 9 & 5. $97-5484$ \\
\hline & 97 & 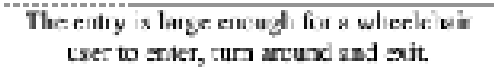 & 6 & $4971-1.457$ \\
\hline & 104 & 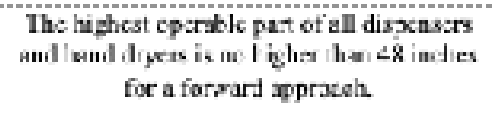 & 6 & $49.7 J-69.52$ \\
\hline & 105 & 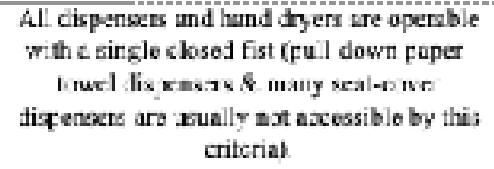 & 7 & $4993-7855$ \\
\hline $\begin{array}{l}\text { Entrgency } \\
\text { Rgrws }\end{array}$ & 124 & 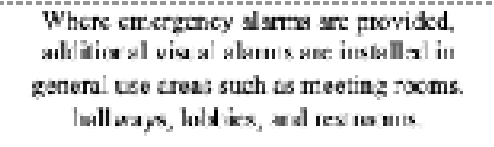 & 5 & $39.9 \mathrm{~J}-\mathrm{E0}: 3$ \\
\hline \multirow{2}{*}{$\begin{array}{l}\text { Exum Roocas/ } \\
\text { Aexes to } \\
\text { Primiany Carp }\end{array}$} & 129 & $\begin{array}{c}\text { There is } \mathbf{2} \text { me:hed io weigh a whalchair- } \\
\text { bee. }\end{array}$ & 6 & $4979-6952$ \\
\hline & 131 & 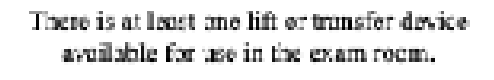 & .0 & $55.13 \quad 59.93$ \\
\hline \multirow[t]{6}{*}{$\begin{array}{l}\text { Lab Specimen } \\
\text { Rim an }\end{array}$} & 137 & 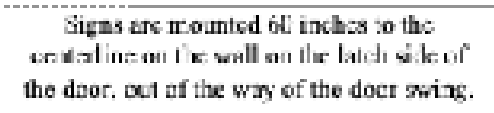 & 8 & $\pi \leq 7-87.00$ \\
\hline & 143 & 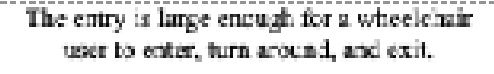 & 8 & $\pi-47-87.0$ \\
\hline & 150 & $\begin{array}{l}\text { The highest cpsciale par of all disxasers } \\
\text { and hard dryars is no highe: thas } 18 \text { irehes. }\end{array}$ & 6 & $49.79-69.52$ \\
\hline & $1 \hat{1}$ & 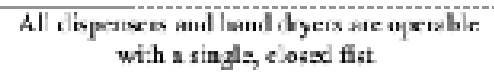 & 7 & $3991-7255$ \\
\hline & 152 & 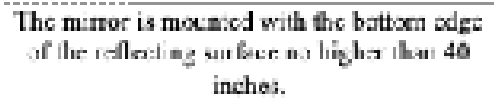 & 7 & $59.9 \mathrm{~J}-78.55$ \\
\hline & & 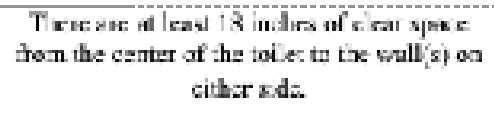 & 3 & $3991-10.7$ \\
\hline
\end{tabular}


Effect of Retrofitting on Usability Scores

\section{PARAMETRIC DATA}

When testing if the original purpose of the building affected categorical scores, a t-test was conducted for parametric data including scores in mobility, sensory, overall, and N/A adjusted scores. Of the facilities evaluated, seven were built for the purposes of housing a medical office and three were retrofitted to house a medical office.

There was a statistical trend observed when comparing the means of the two groups that tested, the mean of the two groups for the sensory score was inconclusive.

\section{NONPARAMETRIC DATA}

A separate test for nonparametric cognitive data was conducted using a Wilcoxon-Mann-Whitney Ranked Sums Test using the median of the results. A box plot is used to display these results. This test indicated significant differences between the ranked mean score of the two groups, suggesting that building built with the purposes of housing medical offices score better in the Cognitive Section of the OHCUP $(Z=-1.708, p=0.044)$.

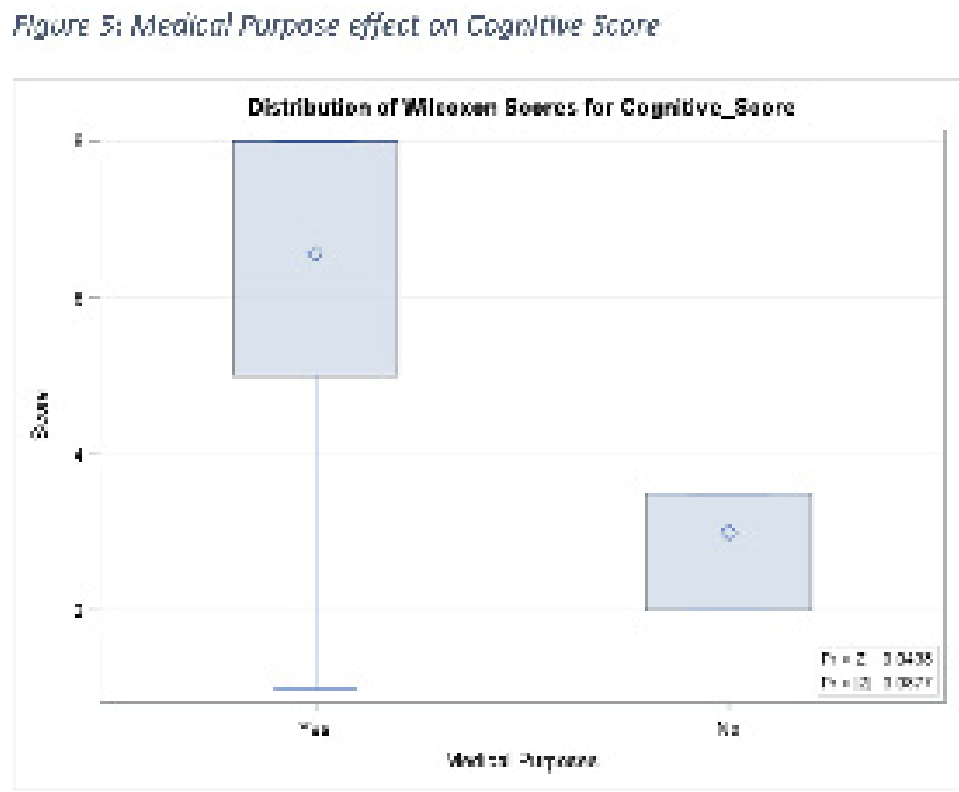

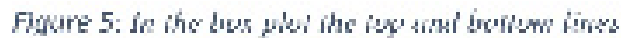
represeni ihe inininsin und maximsin ivalues, the

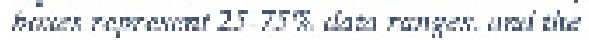
diawow indir.xted the means of the respective nesuler fists liser'r Ciuide: The NPARIWAY Proredure, 2019j. indicated N/A adjusted scores, mobility score, and overall score was higher for building built with the purpose of housing a medical office. The mean for $\mathrm{N} / \mathrm{A}$ adjusted score of buildings built for the purpose of housing medical offices was $76.71 \%(S D=0.076$ ) and the mean of N/A adjusted score for retrofitted medical offices was $65.66 \%(\mathrm{SD}=0.118) ; \mathrm{t}(8)=1.81$, $p=0.054$. The mean for mobility score of buildings built for the purpose of housing medical offices was $85.50 \%(S D=0.060)$ and the mean of mobility score for retrofitted medical offices was $77.10 \%$ (SD = $0.088) ; \mathrm{t}(8)=1.77, \mathrm{p}=0.057$. The mean overall score of buildings built for the purpose of housing medical offices was $84.80 \%$ (SD $=0.053$ ) and the mean of overall scores for retrofitted medical offices was $79.00 \%(S D=0.075) ; t(8)=1.42, p=0.097$. Although

\section{DISCUSSION}

This study aimed to produce a usability profile among a sample of rural outpatient health care facilities. Once adjusted for inapplicable items, the mean mobility, sensory, and cognitive scores of the facilities were $73.49 \%, 69.86 \%$, and $81.97 \%$, respectively. The NA adjusted score of the facilities had a mean of $73.40 \%$. These results are not significantly different $(p=0.471)$ from that of broader research on state-level ADA compliance. A South Carolina study found facilities to be $70.00 \%$ compliant on evaluated ADA items using a 93-item tool, which did not evaluate inapplicable items. Availability of patient lift/transfer devices, accessible restrooms, exam rooms and parking lots are 
consistently found non-compliant in both this study and broader research on the topic. ${ }^{11}$ This research also identified counters, lab specimen rooms, and signage as consistent areas of non-compliance.

This research confirms that year of construction is positively correlated with the facility usability and/or accessibility. ${ }^{12}$ To understand the role that retrofitting plays on accessible design an additional factor, original purpose, was evaluated to measure the effect on usability. Results were inconclusive due to the lack of existing research on the topic and the small sample size of this research, although within the sample, retrofitted buildings exhibited significantly lower scores in cognitive accessibility and suggested a similar trend in mobility, N/A adjusted, and overall scores.

The OHCUP tool is a thorough evaluation comprised of 159 pertinent ADA items which takes two hours to complete. ${ }^{8}$ Understanding commonly non-compliant items from that tool, in the form of an abbreviated version, may serve as a practical evaluation for researchers and health care administrators. The results of this study confirm expected areas of ADA non-compliance and reveal additional itemlevel ADA non-compliance. Together these results provide a framework of pertinent and commonly non-compliant ADA items in rural outpatient health care facilities. Further research may seek to validate an abbreviated tool comprised of commonly noncompliant ADA features that are considered pertinent to usability. Additionally, research may seek to further understand whether rural facilities score significantly different from facilities generally.

The small sample size limits the ability of the study to produce conclusive results about the usability profile of outpatient health care clinics in rural West Virginia, the role retrofitting plays in accessibility scores, and the inference of overall similarity to broader research. In using the results of this study to conduct further research, the limited characteristics of rural health care facilities would be a limitation. For example, elevators were only present in two facilities and stairs only in three. Preliminary research on the usability of these unevaluated features would be necessary before building on these results. In addition, this study is subject to limitations inherent in the use of a research network. Although the WVPBRN has no specific requirement to become a member, it is possible that the results are skewed by the fact that all participating clinics are consistently willing subjects of research activity.

In conclusion, a sample of rural outpatient health care facilities indicate results consistent with broader research on statewide ADA compliance. Facilities evaluated exhibit similar overall scores and the same general areas of non-compliance. This research highlights additional areas of concern, both generally and on an item-specific basis. Also, a relationship between accessibility and year of construction was further confirmed. Conclusions of how retrofitting affects health care usability require additional research. These results are a framework for answering questions about rural accessibility and risk factors of ADA non-compliance, as well as conducting succinct accessibility assessments to be used by researchers and health care administrators. Such research is needed to ensure health care is accessible for all citizens regardless of their level of ability.

\section{AUTHOR AFFILIATIONS}

1. West Virginia University, Morgantown, West Virginia

\section{REFERENCES}

1. Americans With Disabilities Act of 1990, Pub. L. No. 101-336, 104 Stat. 328 (1990).

2. Pharr J, Bungum T. Health disparities experienced by people with disabilities in the United States: a behavioral risk factor surveillance system study. Glob J Health Sci. 2012;4(6).

3. Morrison EH, George V, Mosqueda L. Primary care for adults with physical disabilities: perceptions from consumer and provider focus groups. Fam Med. 2008;40(9):645.

4. Buzza C, Ono SS, Turvey C, Wittrock S, Noble $M$, Reddy $G$, Reisinger HS. Distance is relative: unpacking a principal barrier in rural health care. Journal of General Internal Medicine. 2011;26(S2):648-654.

5. Rural health for West Virginia Introduction - Rural Health Information Hub. Ruralhealthinfo.org. https://www.ruralhealthinfo.org/states/west- 
virginia. Published 2019. Accessed September

25, 2019.

6. U.S. Census Bureau QuickFacts: West Virginia.

Census Bureau QuickFacts. https://www.census.

gov/quickfacts/WV. Published 2019. Accessed

September 25, 2019.

7. Christiadi, Deskins J, Lego B. Population trends In West Virginia through 2030. Morgantown: WVU

Research Corporation; 2014. http://busecon.

wvu.edu/bber/pdfs/BBER-2014-04.pdf. Accessed

September 25, 2019.

8. Drum CE, Horner-Johnson W, Walsh ES.

Construction and validation of the Outpatient

Health Care Usability Profile (OHCUP). Disability

and Health Journal. 2012;5(4):292-297.

9. Graham CL, Mann JR. Accessibility of primary care physician practice sites in South Carolina for people with disabilities. Disability Health Journal. 2008;1:209-214.LIIII

10. Skillman SM, Palazzo L, Keepnews D, Hart LG. Characteristics of registered nurses in rural versus urban areas: implications for strategies to alleviate nursing shortages in the United States. The Journal of Rural Health. 2006;22(2):151-157. LIIII

11. Mudrick NR, Breslin ML, Liang M, Yee S. Physical accessibility in primary health care settings: results from California on-site reviews. Disability and Health Journal. 2012;5(3):159-167.

12. Pharr J, Chino M. Predicting barriers to primary care for patients with disabilities: a mixed methods study of practice administrators. Disability and Health Journal. 2013; 6(2):116-123. 